OPEN ACCESS

Edited by:

Bruno Etain,

Paris Diderot University, France

Reviewed by:

Stefan Borgwardt,

University of Basel, Switzerland

Paul Stokes,

King's College London, United

Kingdom

*Correspondence:

Jie-Yu Chuang

hmm4812@gmail.com

Specialty section:

This article was submitted to Mood and Anxiety Disorders, a section of the journal

Frontiers in Psychiatry

Received: 07 March 2017 Accepted: 22 June 2017

Published: 11 July 2017

Citation:

Chuang J-Y, Hagan CC, Murray GK, Graham JME, Ooi $C$, Tait $R$, Holt RJ,

Elliott $R$, van Nieuwenhuizen $A O$,

Bullmore ET, Lennox BR,

Sahakian BJ, Goodyer IM and Suckling J (2017) Adolescent Major Depressive Disorder: Neuroimaging Evidence of Sex Difference during an Affective Go/No-Go Task.

Front. Psychiatry 8:119. doi: 10.3389/fpsyt.2017.00119

\section{Adolescent Major Depressive Disorder: Neuroimaging Evidence of Sex Difference during an Affective Go/No-Go Task}

\author{
Jie-Yu Chuang ${ }^{1 *}$, Cindy C. Hagan ${ }^{1,2,3}$, Graham K. Murray1,4,5, Julia M. E. Graham¹, Cinly \\ Ooi $^{1}$, Roger Tait ${ }^{5}$, Rosemary J. Holt' ${ }^{1}$, Rebecca Elliott ${ }^{6}$, Adrienne O. van Nieuwenhuizen ${ }^{7}$, \\ Edward T. Bullmore ${ }^{1}$, Belinda R. Lennox ${ }^{8}$, Barbara J. Sahakian ${ }^{1,5}$, Ian M. Goodyer ${ }^{1}$ and \\ John Suckling ${ }^{1,4,5}$

\begin{abstract}
${ }^{1}$ Department of Psychiatry, University of Cambridge, Cambridge, United Kingdom, ${ }^{2}$ California Institute of Technology, Pasadena, CA, United States, ${ }^{3}$ Department of Psychology, Columbia University, New York, NY, United States, ${ }^{4}$ Cambridgeshire and Peterborough NHS Foundation Trust, Cambridge, United Kingdom, ${ }^{5}$ Behavioural and Clinical Neuroscience Institute, Cambridge, United Kingdom, ${ }^{6}$ Institute of Brain, Behaviour and Mental Health, University of Manchester, Manchester, United Kingdom, ${ }^{7}$ University of Cambridge, Cambridge, United Kingdom, ${ }^{8}$ Department of Psychiatry, University of Oxford, Oxford, United Kingdom
\end{abstract}

Compared to female major depressive disorder (MDD), male MDD often receives less attention. However, research is warranted since there are significant sex differences in the clinical presentation of MDD and a higher rate of suicide in depressed men. To the best of our knowledge, this is the first functional magnetic resonance imaging (fMRI) study with a large sample addressing putative sex differences in MDD during adolescence, a period when one of the most robust findings in psychiatric epidemiology emerges; that females are twice as likely to suffer from MDD than males. Twenty-four depressed and 10 healthy male adolescents, together with 82 depressed and 24 healthy female adolescents, aged 11-18 years, undertook an affective go/no-go task during fMRI acquisition. In response to sad relative to neutral distractors, significant sex differences (in the supramarginal gyrus) and group-by-sex interactions (in the supramarginal gyrus and the posterior cingulate cortex) were found. Furthermore, in contrast to the healthy male adolescents, depressed male adolescents showed decreased activation in the cerebellum with a significant group-by-age interaction in connectivity. Future research may consider altered developmental trajectories and the possible implications of sex-specific treatment and prevention strategies for MDD.

Keywords: adolescent major depressive disorder, affective go/no-go task, cerebellum, supramarginal gyrus, sex difference

\section{INTRODUCTION}

\section{Sex Differences in Major Depressive Disorder (MDD)}

The incidence of MDD for girls rises from age 11 to 13 years until by age 15 one of the most robust findings in psychiatric epidemiology emerges; that females are twice as likely to suffer from MDD than males (although this predominance might disappear after age 55 years) (1). Possible explanations 
for sex differences in the incidence of adolescent MDD include: girls having more negative thinking styles, ruminating on interpersonal and body image events, having greater hormone fluctuations, reporting more negative events and sexual abuse, a higher vulnerability to inflammation (2), and estrogen-induced stress response enhancement of the prefrontal cortex (3). The genetic risk for MDD also differs strikingly between sexes with more heritability in women (4). In terms of other risk factors, social stress is closely related to female MDD, whereas low self-esteem is more likely to be related to male MDD (5). Furthermore, looking after small children is associated with greater risk of MDD in women (6) whereas men are more sensitive to the depressogenic effects of divorce, separation, and occupational problems (7). Consequently, research into MDD occurring at this early stage of adolescence avoids these complicating social factors.

Despite strong evidence suggesting poor outcomes, male $\mathrm{MDD}$ is underrepresented in the extant literature. Men are more liable to persistent depression whereas women tend to suffer from a more episodic disorder (8). Depressed men are also more likely to commit suicide (9) and abuse substances (10) than depressed women. Suicidal attempts and substance abuse have been related to poor cognitive control $(11,12)$. Significant sex differences have been found in the cognitive control of emotion (13). Taken together, exploration of cognitive control, and especially of emotional cognitive control, might facilitate an understanding of sex differences in MDD.

\section{Cognitive Control in MDD}

Cognitive control can be defined as neurocognitive processes important for achieving goals, particularly when adaptive adjustment is needed in response to changing environmental demands (14). The possible causal relationship between impaired cognitive control and MDD was proposed as early as Beck's Cognitive Theory of Depression in 1979 (15). Indeed, impaired cognitive control has been associated with the vulnerability, onset, and maintenance of MDD (16). It has also been suggested that persisting cognitive deficits lead to poor psychosocial functioning and hence poor quality of life in remitted depressed patients.

This study used functional magnetic resonance imaging (fMRI) to explore cognitive control among emotional distractions during a widely used affective go/no-go (AGNG) task. In this task, participants responded by button press to target ("go") stimuli that were emotionally valent (e.g., sad) while inhibiting their response to distractor ("no-go") stimuli of a different valence (e.g., happy). The cingulate, inferior frontal gyrus, and insula cortex are most frequently activated during the inhibition of emotional distractors in the AGNG task (17-25). These three regions are also commonly reported in non-affective go/ no-go studies when comparing no-go and go events (26-30) with additional regions such as the middle temporal gyrus, cerebellum and the striatum frequently reported in adolescents (24, 31-36).

Compared to healthy adults, depressed adults show increased activation in the right lateral orbitofrontal cortex and bilateral anterior temporal cortex in response to sad versus neutral distractors (37) which indicates an activation bias toward negative information. Nevertheless, our recently published study using the same task found aberrant brain activation in the orbitofrontal cortex of female adolescents with MDD in response to the happy versus neutral distractors (38). Consequently, it is not clear whether happy, sad, or both distractors elicit aberrant brain responses in adolescents with MDD.

To the best of our knowledge, this is the first fMRI study specifically addressing aberrancy in brain activation in males with MDD, and sex differences in cognitive control in adolescents with MDD. It was hypothesized that there would be a significant sex difference in brain activation associated with cognitive control in the affected group. Despite using an uncorrected statistical threshold, a previous fMRI study located the sex differences in cognitive control responding to negative stimuli to the supramarginal gyrus, amygdala, and orbitofrontal cortex (13). Interestingly, these regions are also among the core areas of pathology of MDD according to Mayberg's limbic-cortical dysregulation model (39). Sex differences in cognitive control in depressed patients would help to explain the difference in the manifestation of MDD in males and females. Specifically, we hypothesized that groupby-sex interactions in brain activation subserving emotional cognitive control would be found in the aforementioned brain regions: the supramarginal gyrus, amygdala, and orbitofrontal cortex. However, given the lack of previous studies, we conducted whole-brain analysis to identify patterns of task-induced activity and then tested for group-by-sex interactions in those regions. Initially, all participants were investigated, followed by an analysis in male participants alone. Results from the female participants alone have been published elsewhere (38).

\section{MATERIALS AND METHODS}

\section{Participants}

Patients with a diagnosis of MDD were recruited from the Improving Mood with Psychoanalytic and Cognitive Therapies (IMPACT), a pragmatic effectiveness clinical trial (40) in East Anglia, North London, and North West England, with patients randomized to one of three different treatment arms to determine the short-to-medium term efficacy of conversational therapies. A subsample of patients from the East Anglia region were invited to participate in an adjunctive study, MR-IMPACT, aimed at exploring the neural mechanisms underlying MDD and recovery following treatment using MRI (41). Healthy control participants matched for age, sex, and handedness were also recruited in the MR-IMPACT study (41). Randomization was first performed in patients, then MRI neural images were taken, which were followed by conversational therapies.

General inclusion criteria for patients in the IMPACT trial (40) and MR-IMPACT study (41) were: aged 11 through 17 years; diagnosis of current moderate-to-severe Diagnostic and Statistical Manual of Mental Disorders (DSM-IV) MDD, as determined by patient and parent interviews with the Kiddie Schedule for Affective Disorders and Schizophrenia-Present and Lifetime version; and score of 27 or above on the self-reported Moods and Feelings Questionnaire (42). Exclusion criteria for the IMPACT trial (40) included: generalized learning difficulties; pervasive developmental disorder; bipolar I disorder; schizophrenia; eating disorder; pregnancy; and currently taking a medication that may 
interact with a selective serotonin reuptake inhibitor. Additional exclusion criteria of the MR-IMPACT study for all participants (i.e., including controls) were as follows: alcohol dependence; drug dependence; MRI contraindication; brain abnormality; and intolerance to the MRI environment (41).

Overall, 126 patients and 40 controls participated in the study. Ninety-four female patients and 29 female controls were enrolled, although some participants were subsequently excluded from the analysis for the following reasons: brain abnormality ( 1 patient), dental braces (7 patients and 2 controls), schizophrenia comorbidity (1 patient), excessive ( $>3$ SDs) motion during fMRI scanning (1 patient and 2 controls), and poor ( $>3$ SDs) behavioral performance on the AGNG task ( 2 patients and 1 control). Thirtytwo male patients and 11 male controls were enrolled. Similarly, some male participants were excluded for the following reasons: brain abnormality (one patient and one control), dental braces (three patients), schizophrenia comorbidity (two patients), excessive motion during scanning (one patient), and poor behavioral performance on the AGNG task (one patient). Overall, 82 female patients and 24 female controls along with 24 male patients and 10 male controls were included in the analysis. The study was conducted in accordance with the Declaration of Helsinki (https://www.wma.net/what-we-do/medical-ethics/declarationof-helsinki/). Ethical approval was given by the Cambridgeshire 2 Research Ethics Committee, UK (REC reference: 09/H0308/168).

As the study recruited participants through a pragmatic effectiveness trial, more women than men were enrolled in this study resulting in an unbalanced design with restricted power for addressing sex effects. Likewise, the number of male relative to female controls enrolled was fewer.

\section{Affective Go/No-Go Task}

Happy, sad, and neutral words were presented to participants during fMRI data acquisition using a block paradigm task design (37) (Figure 1). Words did not differ in terms of length or usage frequency (43). There were seven types of blocks each repeating three times, consisting of randomly ordered targets/distractors (10 of each type): sad/neutral (SN), sad/happy (SH), neutral/ sad, neutral/happy, happy/sad (HS), happy/neutral (HN), and neutral italic/plain. Equal numbers of happy and sad words were used with mood induction unlikely to occur. As a result, neural responses of the participants were likely to be related to cognitive control instead of affective response. The inter-block interval was $12 \mathrm{~s}$ with the first $4 \mathrm{~s}$ of each block used to present the instructions for that block. Each word was presented for $450 \mathrm{~ms}$ with a $750 \mathrm{~ms}$ interstimulus interval (41). Participants were asked to press a button with their right index finger when presented with a target word ("go") and to inhibit responses to distractor words ("no-go"). All participants completed a go/no-go practice task (living versus non-living stimuli) prior to scanning. The following analyses were based on two contrasts: a happy distractor contrast (SH-SN) and a sad distractor contrast (HS-HN) with targets fixed and distractors differing in valence.

\section{Behavioral Data Analysis}

Behavioral output tailored to the happy distractor contrast and the sad distractor contrast was recorded to capture three variables:

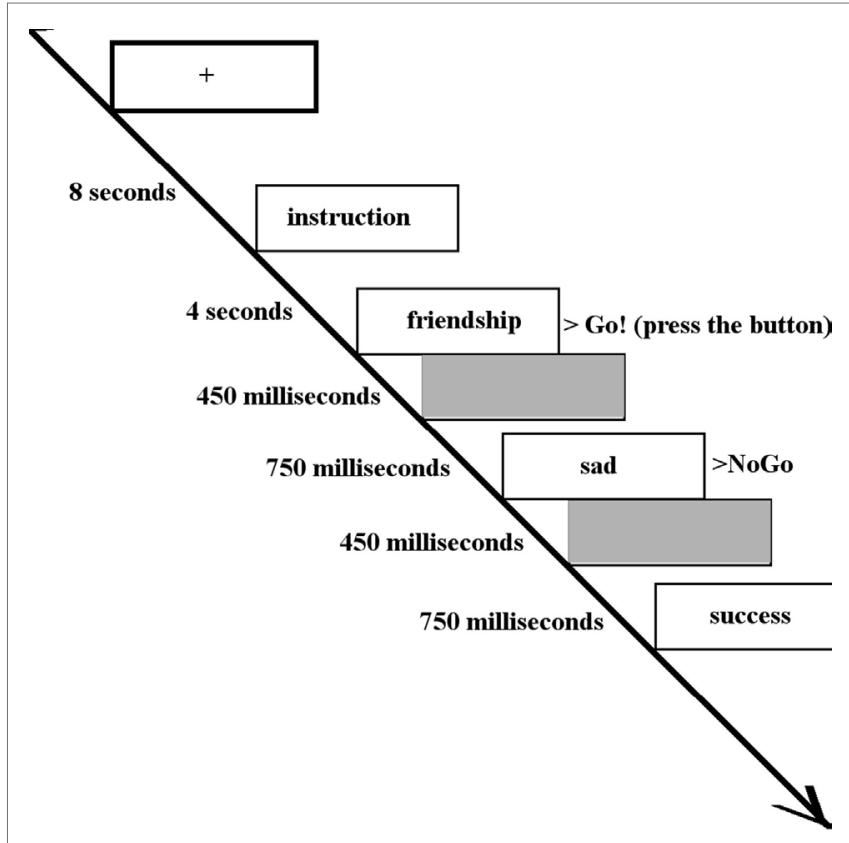

FIGURE 1 | The inter-block interval was $12 \mathrm{~s}$ with the first $4 \mathrm{~s}$ of each block used to present the instructions (in this case, "Press for happy words. Ignore sad words."). Each word was presented for $450 \mathrm{~ms}$ with a $750 \mathrm{~ms}$ interstimulus interval. Participants were asked to press a button when presented with a target word (in this case, happy words) and inhibit responses to distractor words (in this case, sad words).

mean response time of correct go, incorrect go (omission error), and incorrect no-go (commission error). For instance, mean response time of the sad distractor contrast was defined as the mean reaction time of the HS condition minus the mean reaction time of the HN condition. Likewise, omission error of the happy distractor contrast was defined as the number of the omission errors in the $\mathrm{SH}$ condition minus the number of the omission errors in the SN condition. The timing of responses was measured when participants released the button. Analysis of covariance was performed in SPSS (Statistical Package for Social Science, version 21) on the behavioral measures, with group (depressed/ healthy) and sex as independent variables, and age as a covariate. Group, sex, and age effects, as well as group-by-sex and groupby-age interactions were then explored in a single model with a statistical threshold for significance of $p<0.05$.

\section{fMRI Analysis \\ fMRI Data Acquisition}

Participants were scanned on a 3-T Magnetom Trio Tim MRI scanner (Siemens, Surrey, England) at the Wolfson Brain Imaging Centre, University of Cambridge, UK. Thirty-two slices of data parallel to the anterior-posterior commissure comprised each three-dimensional volume acquired continuously during the task. Acquisition parameters were: echo time, $\mathrm{TE}=30 \mathrm{~ms}$; repetition time, $\mathrm{TR}=2 \mathrm{~s}$; flip angle $=78^{\circ}$; field of view $=192 \mathrm{~mm} \times 120 \mathrm{~mm}$; and $3.0 \mathrm{~mm} \times 3.0 \mathrm{~mm} \times 3.0 \mathrm{~mm}$ voxel size with an interleaved slice acquisition (41). 
Within-Subject fMRI Data Preprocessing

Imaging data were preprocessed with FEAT (FMRI Expert Analysis Tool, version 6.00) in FSL 5.0.6 (FMRIB's Software Library, www.fmrib.ox.ac.uk/fsl). Participant head motion was corrected with MCFLIRT (Motion Correction FMRIB's Linear Image Registration Tool) (44), interleaved slice timing was corrected with Fourier-space time-series phase-shifting, nonbrain tissue was removed by Brain Extraction Tool (45), spatial smoothing was performed with a Gaussian kernel of FWHM $6 \mathrm{~mm}$, grand-mean intensity of data was normalized by a single multiplicative factor, and high-pass temporal filtering with $90 \mathrm{~s}$ cutoff was performed.

\section{Between-Subject fMRI Data Analysis}

Following initial within-subject (first level) analysis to generate $z$-statistic maps, all maps were normalized to the standard Montreal Neurological Institute (MNI) space (46) by FLIRT (FMRIB's Linear Image Registration Tool) $(44,47)$.

To accommodate the possibility of unequal variances between males and females due to the unbalanced design, we used the Aspin-Welch statistic and permutation inference, as implemented in the tool Permutation Analysis of Linear Models (PALM), part of the FSL package (https://fsl.fmrib.ox.ac.uk/fsl/fslwiki/PALM) (48).

With all participants, a whole-brain Aspin-Welch unequal variance test controlling for age determined significant mean activation and deactivation patterns of the two contrasts such that for the happy (or sad) distractor contrast, the activation pattern referred to the brain regions more activated to the $\mathrm{SH}$ (or HS) condition than the $\mathrm{SN}$ (or $\mathrm{HN}$ ) condition, and the deactivation pattern referred to the brain regions more activated to the $\mathrm{SN}$ (or HN) condition than the SH (or HS) condition. Subsequent between-subject analysis was restricted to these mean activated or deactivated regions. The Aspin-Welch unequal variance test was then performed with group (depressed/healthy) and sex as independent variables, and age as a covariate. Group, sex, and age effects as well as group-by-sex and group-by-age interactions were examined. Significant statistical results were identified using threshold-free cluster enhancement at a threshold of $p<0.05$, family-wise error rate corrected.

To explore the aberrancy of activation within male participants, data were subsequently analyzed solely in male participants. Since patients and controls did not differ much in sample size, Aspin-Welch unequal variance test was not used in this analysis. Instead, FEAT with FLAME (FMRIB's Local Analysis of Mixed Effects) was used in a whole-brain one-sample $t$-test controlling for age, to determine significant patterns of mean activation and deactivation. Then, restricting the analysis to these mean activated or deactivated regions, group effects controlling for age were explored. Again, significant statistical results were obtained using TFCE at a threshold of $p<0.05$, family-wise error rate corrected.

\section{Psychophysiological Interactions (PPIs)}

Psychophysiological interaction analysis identifies regions that increase their connectivity with a seed region of interest during task performance (49). That is, using the fMRI data with a seed region specified, PPI detects brain areas whose activity depends on an interaction between a psychological factor (task performance) and physiological factor (time course of the seed region) (49).

For consistency with univariate approaches, regions showing significant group effects in between-subject fMRI analyses were used as seeds. First, this seed region was transformed into the individual fMRI acquisition space of each participant using FNIRT (FMRIB's non-linear image registration tool). It is likely that the significant group effect might reside in a relative small region compared to the whole-brain. The precision of this transformation in such a small region is critical to the following analyses, and thus non-linear (FNIRT) instead of linear (FLIRT) transformation was used to ensure sufficient deformation (http:// fsl.fmrib.ox.ac.uk/fsl/fslwiki/FNIRT) at the cost of computation time. The time course of the transformed region was extracted from each individual dataset.

Second, within-subject analysis was carried out with the time course extracted from the seed as a factor denoted "physiological regressor." The happy distractor contrast and the sad distractor contrast denoted the "psychological regressors." The interaction between the physiological and psychological regressors was then defined as the PPI. Finally, a between-subject FEAT analysis was performed with group effects, age effects, and the groupby-age interactions examined. Significant statistical results were obtained using TFCE at a threshold of $p<0.05$, family-wise error rate corrected.

\section{RESULTS}

\section{Demographic and Behavioral Results}

There were no significant sex differences in demographic and behavioral characteristics (age, intelligence, handedness, trait anxiety, MDD severity, number of commission errors, number of omission errors, reaction time) with the exception that female adolescents had higher levels of state anxiety than male adolescents (Table 1). There were no significant sex differences $(t / \mathrm{df} / p=1.50 / 34 / 0.142)$ in antidepressant usage (mean fluoxetine equivalent dose $\times$ duration): $19.52 \mathrm{mg} \times 2.43$ months in girls and $18.41 \mathrm{mg} \times 1.34$ months in boys. There was a significant age effect $[F(1,134)=5.250, p=0.024]$ with older participants taking a longer time to respond to the happy targets (in the sad distractor contrast, i.e., during the sad versus neutral distractors) (Table 2; Figure 2).

\section{Results from the Analysis of All Participants}

No significant within-group mean activations or deactivations were found in response to the happy distractor contrast suggesting similar brain activation patterns occurring for happy compared to neutral distractors. In response to the sad distractor contrast, significant within-group mean activation occurred in regions of posterior cingulate, supramarginal gyrus and dorsolateral prefrontal cortex, similar to the well-acknowledged frontoparietal activated region in the go/no-go task (50). No significant mean deactivation regions were identified (Table 3; Figure 3). 
TABLE 1 | Between-sex differences in demographic and baseline characteristics.

\begin{tabular}{|c|c|c|c|c|c|c|}
\hline & \multicolumn{3}{|c|}{ Depressed patients } & \multicolumn{3}{|c|}{ Healthy controls } \\
\hline & $\begin{array}{l}\text { Females, } \\
\text { mean/SD }\end{array}$ & $\begin{array}{l}\text { Males, } \\
\text { mean/SD }\end{array}$ & $\begin{array}{c}\text { Between-sex } \\
\text { difference, } t / d f / p\end{array}$ & $\begin{array}{l}\text { Females, } \\
\text { mean/SD }\end{array}$ & $\begin{array}{l}\text { Males, } \\
\text { mean/SD }\end{array}$ & $\begin{array}{c}\text { Between-sex } \\
\text { difference, } t / d f / p\end{array}$ \\
\hline Number & 82 & 24 & - & 24 & 10 & - \\
\hline Age (years) & $15.72 / 1.10$ & $15.25 / 1.52$ & $1.68 / 104 / 0.10$ & $15.89 / 1.42$ & $15.26 / 1.22$ & $1.23 / 32 / 0.23$ \\
\hline Estimated WASI IQ & $97.83 / 12.02$ & $98.25 / 9.89$ & $-0.14 / 31.59 / 0.89$ & $100.79 / 10.85$ & $99.60 / 7.96$ & $0.31 / 32 / 0.76$ \\
\hline Edinburgh Handedness Inventory & $58.66 / 54.11$ & $67.92 / 52.50$ & $-0.74 / 104 / 0.46$ & $62.46 / 57.86$ & $60.00 / 58.88$ & $0.11 / 32 / 0.91$ \\
\hline STAI-State & $47.70 / 10.49$ & 39.79/10.05 & $3.28 / 104 / 0.001^{\star \star \star}$ & $28.92 / 6.43$ & $27.50 / 5.64$ & $0.61 / 32 / 0.55$ \\
\hline STAI-Trait & $61.44 / 7.41$ & $57.17 / 10.12$ & $1.92 / 30.57 / 0.06$ & $31.13 / 6.78$ & $29.90 / 6.24$ & 0.49/32/0.63 \\
\hline SMFQ & $18.11 / 5.02$ & $16.38 / 5.20$ & $1.48 / 104 / 0.14$ & 2.63/2.02 & $3.30 / 2.00$ & $-0.89 / 32 / 0.38$ \\
\hline Happy distractor: commission & $1.67 / 3.01$ & $1.00 / 4.74$ & $0.66 / 28.63 / 0.52$ & $1.50 / 2.54$ & $0.30 / 2.45$ & $1.27 / 32 / 0.21$ \\
\hline Happy distractor: omission & $-0.48 / 2.86$ & $-0.04 / 3.56$ & $-0.62 / 104 / 0.54$ & $-1.00 / 2.36$ & $0.10 / 0.99$ & $-1.91 / 31.95 / 0.07$ \\
\hline Happy distractor: reaction time & $-12.63 / 52.28$ & $3.97 / 46.63$ & $-1.40 / 104 / 0.16$ & $-7.64 / 42.14$ & $-6.71 / 66.22$ & $-0.05 / 32 / 0.96$ \\
\hline Sad distractor: commission & $0.91 / 3.21$ & $1.21 / 3.54$ & $-0.39 / 104 / 0.70$ & $0.67 / 4.47$ & $1.40 / 2.55$ & $-0.48 / 32 / 0.63$ \\
\hline Sad distractor: omission & $0.37 / 3.54$ & $0.71 / 3.07$ & $-0.43 / 104 / 0.67$ & $0.33 / 3.19$ & $-0.60 / 2.95$ & $0.79 / 32 / 0.43$ \\
\hline Sad distractor: reaction time & $20.57 / 43.66$ & $9.81 / 46.35$ & $1.05 / 104 / 0.30$ & $32.99 / 43.81$ & $13.52 / 46.75$ & $1.16 / 32 / 0.26$ \\
\hline Commission error - correct targets & $-138.32 / 35.39$ & $-131.79 / 41.49$ & $-0.76 / 104 / 0.45$ & $-152.17 / 20.80$ & $-140.20 / 24.68$ & $-1.45 / 32 / 0.16$ \\
\hline
\end{tabular}

${ }^{* * *} p \leq 0.001 ;$ Bold font are significant results.

TABLE 2 | Behavioral results.

\begin{tabular}{lccc}
\hline Effect & $\begin{array}{c}\text { Commission } \\
(\boldsymbol{F} / \boldsymbol{p})\end{array}$ & $\begin{array}{c}\text { Omission } \\
(\boldsymbol{F} / \boldsymbol{p})\end{array}$ & $\begin{array}{c}\text { Reaction } \\
\text { time (F/p) }\end{array}$ \\
\hline $\begin{array}{l}\text { (A). The happy distractor contrast } \\
\text { Group (depressed/ } \\
\text { healthy) }\end{array}$ & & \\
Sex & $1.342 / 0.249$ & $3.563 / 0.061$ & $0.574 / 0.450$ \\
Age & $1.411 / 0.237$ & $1.801 / 0.182$ & $0.253 / 0.616$ \\
Group $\times$ sex & $0.065 / 0.800$ & $0.195 / 0.659$ & $1.621 / 0.205$ \\
Group $\times$ age & $0.021 / 0.886$ & $0.785 / 0.377$ & $0.745 / 0.390$ \\
(B) The sad distractor contrast & $3.490 / 0.064$ & $0.612 / 0.436$ \\
Group (depressed/ & $0.270 / 0.604$ & $0.116 / 0.734$ & $0.152 / 0.697$ \\
healthy) & & & \\
Sex & $0.805 / 0.371$ & $0.186 / 0.667$ & $1.184 / 0.279$ \\
Age & $1.495 / 0.224$ & $0.032 / 0.858$ & $5.250 / 0.024$ \\
Group $\times$ sex & $0.168 / 0.682$ & $0.843 / 0.360$ & $0.084 / 0.772$ \\
Group $\times$ age & $0.266 / 0.607$ & $0.180 / 0.672$ & $0.214 / 0.644$ \\
\hline
\end{tabular}

${ }^{*} p \leq 0.05$; Bold font are significant results.

Using PALM and restricting the analysis to the mean activation regions described above did not reveal any significant group, age effects, or group-by-age interactions. Consequently, despite the longer reaction times found in the older participants, their brain activation did not differ significantly from the younger participants. A significant sex effect was found in the supramarginal gyrus, and significant group-by-sex interactions were found in the supramarginal gyrus and posterior cingulate (Table 3; Figure 3). Mean percent signal changes were then extracted from regions with significant results. Post hoc inspection of the extracted data revealed that the reductions in activation in males with MDD relative to healthy male adolescents were driving the majority of the significant group $\times$ sex interaction results (Figure 3; Table 4). Although there was a significant sex difference in STAI-S state anxiety (Table 1), no significant correlations between STAI-S and these percent signal changes were found.

\section{Brain Activation in Male Participants}

There were no significant within-group mean activation or deactivations for the happy distractor contrast. However, significant

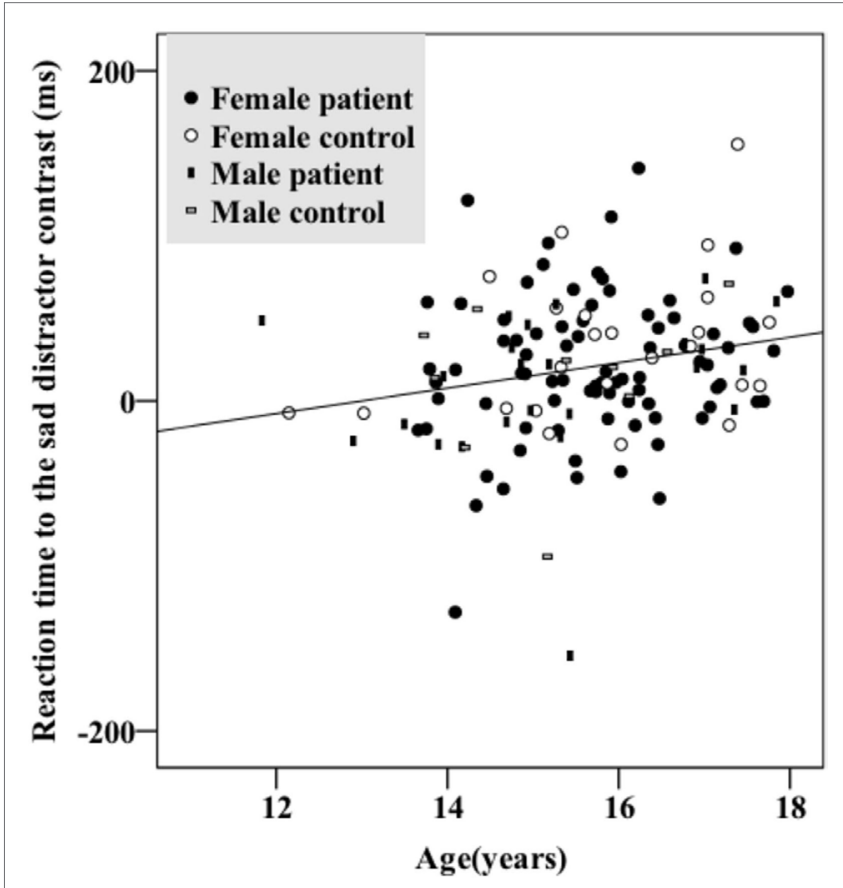

FIGURE 2 | Older participants had longer reaction times responding to the sad distractor contrast. There were no significant group (depressed/healthy) or sex effects. Female patients, female controls, male patients, and male controls all showed similar patterns.

mean activations were found in the frontal pole, middle frontal gyrus, posterior cingulate cortex (PCC), and the cerebellum responding to the sad distractor contrast. Within these mean activation regions, male adolescents with MDD were found to exhibit lower brain activations than healthy male adolescents in the Crus I and Crus II regions of the cerebellum (Table 5; Figure 4).

\section{PPI Analysis of Male Participants}

As the cerebellum was found to show a significant group difference, this region was chosen as a seed region for the PPI analysis. 
TABLE 3 | Significant mean activation, sex effect and group $\times$ sex interactions responding to the sad distractor contrast in all participants.

\begin{tabular}{|c|c|c|c|c|}
\hline Cluster & Cluster size (voxels) & Maximum z value & $\begin{array}{l}\text { Peak Montreal Neurological Institute } \\
\text { coordinates }(X, Y, Z \text { in } \mathrm{mm})\end{array}$ & Location of the peak \\
\hline \multirow[t]{9}{*}{ Mean activation } & 10,237 & 2.82 & $(36,-40,34)$ & Right supramarginal gyrus \\
\hline & 7,804 & 2.5 & $(30,6,44)$ & Right DLPFC \\
\hline & 1,761 & 2.06 & $(-22,-74,-28)$ & Left cerebellum \\
\hline & 668 & 1.8 & $(12,-8,16)$ & Right thalamus \\
\hline & 268 & 1.81 & $(-36,32,34)$ & Left DLPFC \\
\hline & 198 & 1.75 & $(-6,-12,-6)$ & Left thalamus \\
\hline & 64 & 1.67 & $(2,-32,-38)$ & Brain stem \\
\hline & 27 & 1.67 & $(8,-28,-10)$ & Brain stem \\
\hline & 18 & 1.7 & $(-10,-46,-44)$ & Brain stem \\
\hline Sex effect & 18 & 1.72 & $(36,-36,34)$ & Right supramarginal gyrus \\
\hline \multicolumn{5}{|l|}{ Group $\times$ sex } \\
\hline Cluster 1 & 5 & 1.65 & $(64,-30,22)$ & Right supramarginal gyrus \\
\hline Cluster 2 & 10 & 1.66 & $(14,-60,48)$ & Right precuneus cortex \\
\hline Cluster 3 & 32 & 1.84 & $(60,-18,28)$ & Right supramarginal gyrus \\
\hline Cluster 4 & 43 & 1.8 & $(28,-62,32)$ & Right lateral occipital cortex \\
\hline Cluster 5 & 429 & 2.37 & $(32,-42,38)$ & Right supramarginal gyrus \\
\hline Cluster 6 & 429 & 2 & $(-12,-34,38)$ & Left posterior cingulate cortex \\
\hline
\end{tabular}

No significant group or age effects were found. However, there was a significant group-by-age interaction between the cerebellum seed and the superior frontal gyrus (Table 5; Figure 5). The PPI effect showed that compared with younger participants, connectivity between the cerebellum and superior frontal gyrus increased in strength across age in male controls, but decreased in strength with age in males with MDD (Figure 5). Taken together, differential functional responses associated with MDD and age-related changes of brain connectivity were found in the cerebellum of male adolescents.

All of the significant results identified in the primary analysis were checked for medication effects by $t$-tests between the group of patients using antidepressants $(n=36)$ and the group of patients not using antidepressants $(n=70)$. $t$-Statistics, $p$ values, means, and SDs associated with these tests are shown in the Table S1 in Supplementary Material. Patients with and without antidepressant usage did not differ significantly in terms of behavior or brain activation.

\section{DISCUSSION}

In response to the sad distractor contrast, significant sex differences (in the supramarginal gyrus), group-by-sex interactions (in the supramarginal gyrus and the PCC) and group differences in males (cerebellum) were found. Furthermore, a significant group-by-age interaction in connectivity between the cerebellum and superior frontal gyrus was observed.

\section{Response to the Happy Targets Intermixed with the Sad versus Neutral Distractors}

Results from a previous study using an affective go/no-go task suggests that there is no significant developmental change of the reaction time difference between the negative image distractors and the positive or neutral images in the age range of 11-25 years (51). However, another go/no-go overlap task reports significant reaction time differences between fearful face distractors and happy or neutral face distractors in younger adolescents (11- to 12-year olds) which diminished in older adolescents (17- to 18-year olds) (52). Our data instead associated increased age with greater response time differences toward the sad versus neutral word distractors (in the sad distractor contrast, HS-HN) (Table 2; Figure 2). This inconsistency could be related to the fact that neutral targets were used in the previous two studies whereas happy targets were used in our work. Furthermore, all three studies used cross-sectional designs. Future research is warranted before these results can be comprehensively interpreted.

\section{Interaction Effect Regions: The Supramarginal Gyrus}

The supramarginal gyrus is located within the inferior parietal lobe, a region thought to be involved in attention, processing of written language, and working memory of emotional stimuli (53). Several studies suggest a relationship between MDD and supramarginal gyrus $(54,55)$. A meta-analysis indicates aberrant supramarginal gyrus activation toward positive emotional stimuli associated with MDD (54). Furthermore, aberrant connectivity has been shown between the medial prefrontal cortex and the supramarginal gyrus in adolescents with MDD (55).

Compared with women, men have larger total volume of the inferior parietal lobule (supramarginal gyrus and angular gyrus) (56). There is also evidence of sex differences in supramarginal gyrus function. Higher regional homogeneity ( $\mathrm{ReHo}$ ) of the fMRI time series in the supramarginal gyrus has been reported in female compared to male adults (57). In the supramarginal gyrus, men also show higher activation in response to negative words and lower activation in response to positive words as compared with women (58). Moreover, compared to women, hyperactivation of the supramarginal gyrus has been found during the cognitive control of negative stimuli in men (13). Our finding of a sex effect and group-by-sex interaction in the supramarginal gyrus extends these previous results and highlights the supra marginal gurus as a potentially key region contributing to sex differences in MDD. 


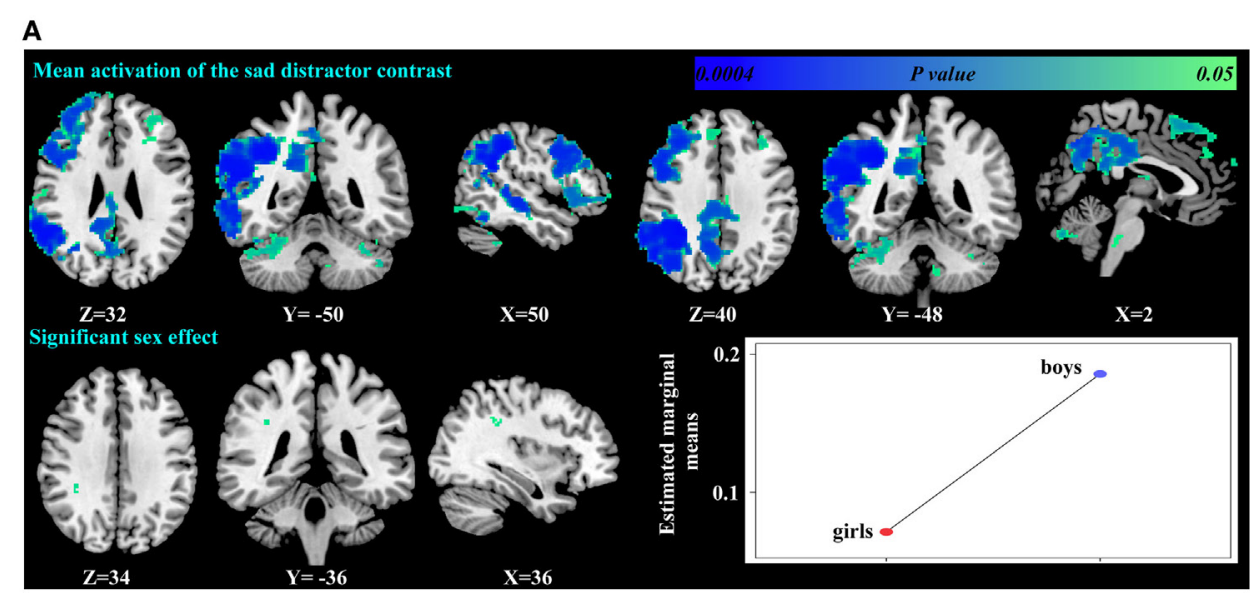

B

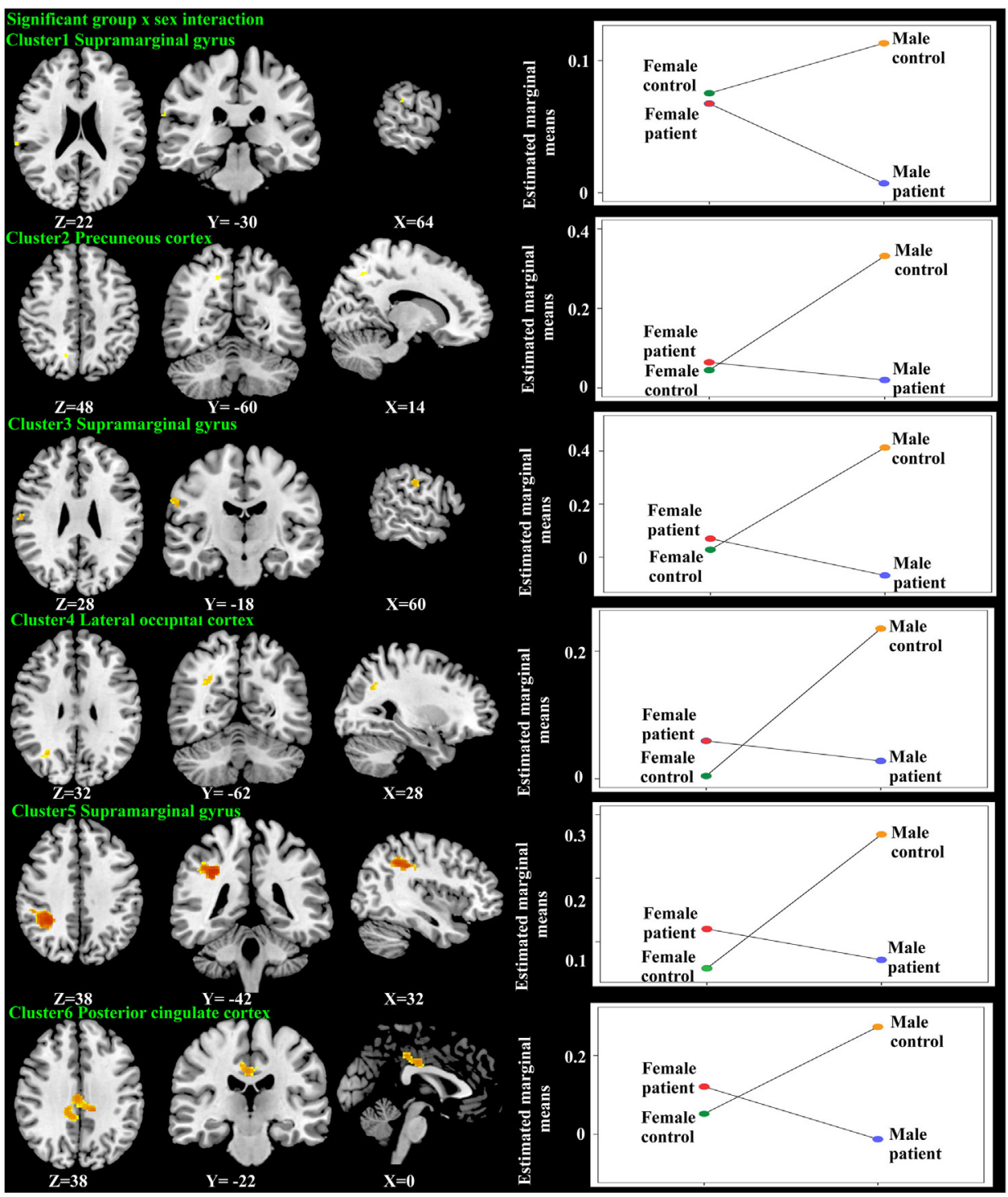

FIGURE 3 | Significant mean activation, sex effect (A) and group-by-sex interaction (B) responding to the sad distractor contrast in all participants. Box plots depicted estimated marginal means of the percent signal changes extracted from the regions showing significant sex effect in the supramarginal gyrus (A), and a group-by-sex interaction in the supramarginal gyrus, precuneus cortex, lateral occipital cortex, and the posterior cingulate cortex (B). 


\section{Interaction Effect Regions: The PCC}

The PCC is involved in risky decision-making (59), daydreaming, autobiographical memory, attention, and conscious awareness (60). This study showed a significant group-by-sex interaction in PCC. Previous literature has associated the PCC with MDD and sex effects; an overactive PCC has been observed in treatmentresistant adult MDD (60), and a meta-analysis also demonstrates that men have larger gray matter volume in the PCC as compared to women (61). However, to the best of our knowledge, no previous study has addressed the group-by-sex interaction in PCC.

\section{Cerebellar Dysfunction in Males with MDD}

Although initially considered as a motor coordinator, the cerebellum is now known to play a role in emotional regulation and cognition, supported by its widespread connections to the limbic system, the frontal, parietal, prefrontal, occipital, and temporal cortex. The cerebellum is activated in a variety of mental activities, including facial recognition, emotion attribution, theory of mind attributions, directed attention, memory, and empathy (62, 63) and has been referred to as the "emotional pacemaker" (64). Indeed, the cerebellar cognitive affective syndrome following posterior cerebellar lobe lesion includes negative symptoms such as passivity, blunted affect, and withdrawal. In an early PET study, Dolan et al. reported increased regional cerebral blood flow of the cerebellar vermis in depressed adult patients with cognitive disturbance (65). Furthermore, in an fMRI meta-analysis, the cerebellum has been identified as an important area of dysfunction in MDD (66). Other meta-analyses suggest decreased ReHo

TABLE 4 | Post hoc tests of the percent signal changes from the regions showing significant group $\times$ sex interactions.

\begin{tabular}{|c|c|c|c|c|}
\hline \multirow[t]{2}{*}{ Cluster } & \multirow{2}{*}{$\begin{array}{l}\text { Post hoc t } \\
\text { value in girls } \\
\text { (comparing } \\
\text { patients with } \\
\text { controls) }\end{array}$} & \multirow{2}{*}{$\begin{array}{l}p \text {-Value } \\
\text { df }=103\end{array}$} & \multirow{2}{*}{$\begin{array}{c}\text { Post hoc } t \\
\text { value in boys } \\
\text { (comparing } \\
\text { patients with } \\
\text { controls) }\end{array}$} & \multirow{2}{*}{$\begin{array}{l}p \text {-Value } \\
\text { df }=31\end{array}$} \\
\hline & & & & \\
\hline \multicolumn{5}{|c|}{ Group $\times$ sex } \\
\hline Cluster 1 & 0.048 & 1.000 & -1.101 & 0.556 \\
\hline Cluster 2 & 0.841 & 0.800 & -3.649 & $0.002^{\star *}$ \\
\hline Cluster 3 & 0.697 & 0.968 & -5.133 & $0.000032^{\star \star \star \star}$ \\
\hline Cluster 4 & 1.585 & 0.230 & -2.987 & $0.01^{\star *}$ \\
\hline Cluster 5 & 1.636 & 0.206 & -3.014 & $0.01^{\star *}$ \\
\hline Cluster 6 & 1.750 & 0.172 & -3.158 & $0.008^{\star \star}$ \\
\hline
\end{tabular}

${ }^{* *} p \leq 0.01 ;{ }^{* * * *} p \leq 0.0001$; Bold font are significant results. in the left cerebellum (67) and aberrant cerebellar activation toward positive and negative emotional stimuli in MDD (54).

It has been proposed that the relatively protracted developmental course of the cerebellum may be associated with its vulnerability to the effects of mental disorders (68). A developmental difference exists between sexes with the total cerebellum volume peaks at age 15.6 years in boys in contrast to 11.8 years in girls (68). A prior study showed hyperactivation of the cerebellum in response to the positive stimuli in depressed compared to healthy adolescents (69). Another study demonstrated aberrant activation of the cerebellum responding to the negative distractor in adolescents with family history of MDD when compared to healthy controls (70). Similarly, we have identified hypoactive cerebellum responding to the sad distractor contrast in male adolescents with MDD.

We demonstrated a significant group-by-age interaction of the connectivity between cerebellum Crus I, Crus II, and the superior frontal gyrus in male adolescents. Superior frontal gyrus along with Crus I and Crus II of the cerebellum (71) is part of the default network. Indeed, a meta-analysis supports the importance of the aberrant resting-state connectivity between the cerebellum and other default network regions responsible for internally oriented and self-referential thinking in MDD (mean age 37.77 years old) (72). Examples include: higher resting-state connectivity between cerebellum and middle temporal gyrus $(73,74)$, and between the cerebellum and superior temporal pole (75). A multivariate pattern analysis also suggested that the resting-state connection of the cerebellum is among the most discriminating regions separating healthy from depressed adults (75). To the best of our knowledge, there is no longitudinal study addressing the interaction between the connectivity of the cerebellum and development. However, similar to adult MDD, fronto-cerebellar dysregulation has been hypothesized to be a pathophysiological mechanism of adolescent MDD (69). Aberrant resting-state connectivity between the cerebellum and other default network regions has also been found in geriatric MDD (76). The developmental trajectory of the connections in the cerebellum awaits further exploration.

\section{Limitations}

Reflecting the skewed prevalence of MDD, the sample size of the male patient group was relatively limited. Furthermore, the number of males in the control group was also limited. Presumably, the restricted number of males might be related to the failure to find significant group-by-sex interactions in the amygdala and

TABLE 5 | Significant fMRI mean activation, group difference, and group $\times$ age interaction of the connectivity between the cerebellum and the superior frontal gyrus responding to the sad distractor contrast.

\begin{tabular}{|c|c|c|c|c|}
\hline Cluster & $\begin{array}{l}\text { Cluster size } \\
\text { (voxels) }\end{array}$ & $\begin{array}{l}\text { Maximum } \\
\text { z value }\end{array}$ & $\begin{array}{l}\text { Peak Montreal Neurological Institute } \\
\text { coordinates }(X, Y, Z \text { in } \mathrm{mm})\end{array}$ & Location of the peak \\
\hline \multicolumn{5}{|l|}{ Male mean activation } \\
\hline Cluster1 & 662 & 3.45 & $(26,4,46)$ & Right middle frontal gyrus \\
\hline Cluster 2 & 1,130 & 3.35 & $(38,48,24)$ & Right frontal pole \\
\hline Cluster 3 & 1,254 & 3.46 & $(-18,-70 .-44)$ & Cerebellum \\
\hline Cluster 4 & 3,540 & 3.41 & $(58,-50,24)$ & Right angular gyrus \\
\hline $\begin{array}{l}\text { Male case-control difference of the activation } \\
\text { map (patient < control) }\end{array}$ & 395 & 3.47 & $(4,-80,-36)$ & Cerebellum \\
\hline Group $\times$ age interaction of the & 560 & 3.21 & $(38,-6,48)$ & Right precentral gyrus \\
\hline
\end{tabular}




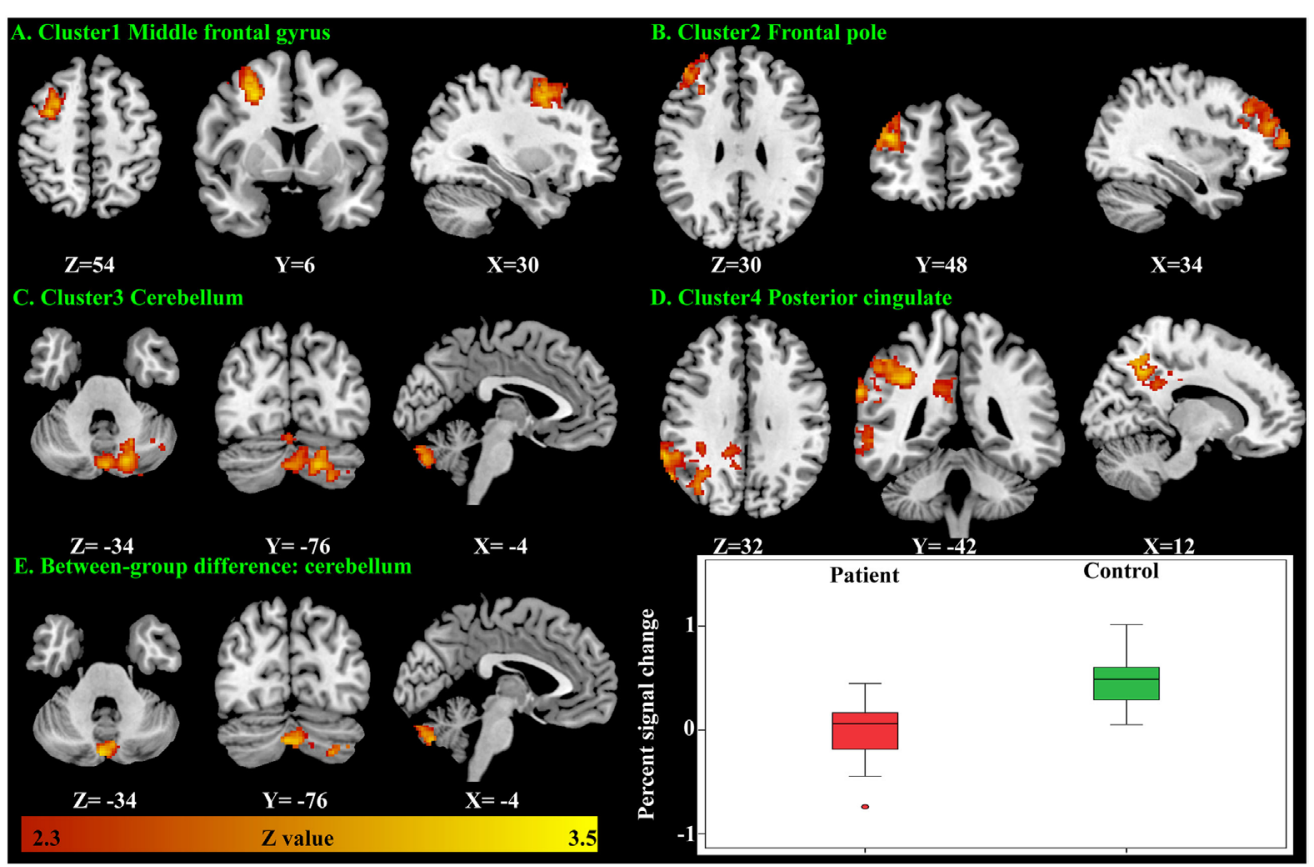

FIGURE 4 | Significant brain activation responding to the sad distractor contrast in the male adolescents. Significant mean activation (A-D) and significant casecontrol difference of these mean activation regions (E). A box plot showed higher brain activation (extracted percent signal change) in the male controls' cerebellum when compared with the male patients.

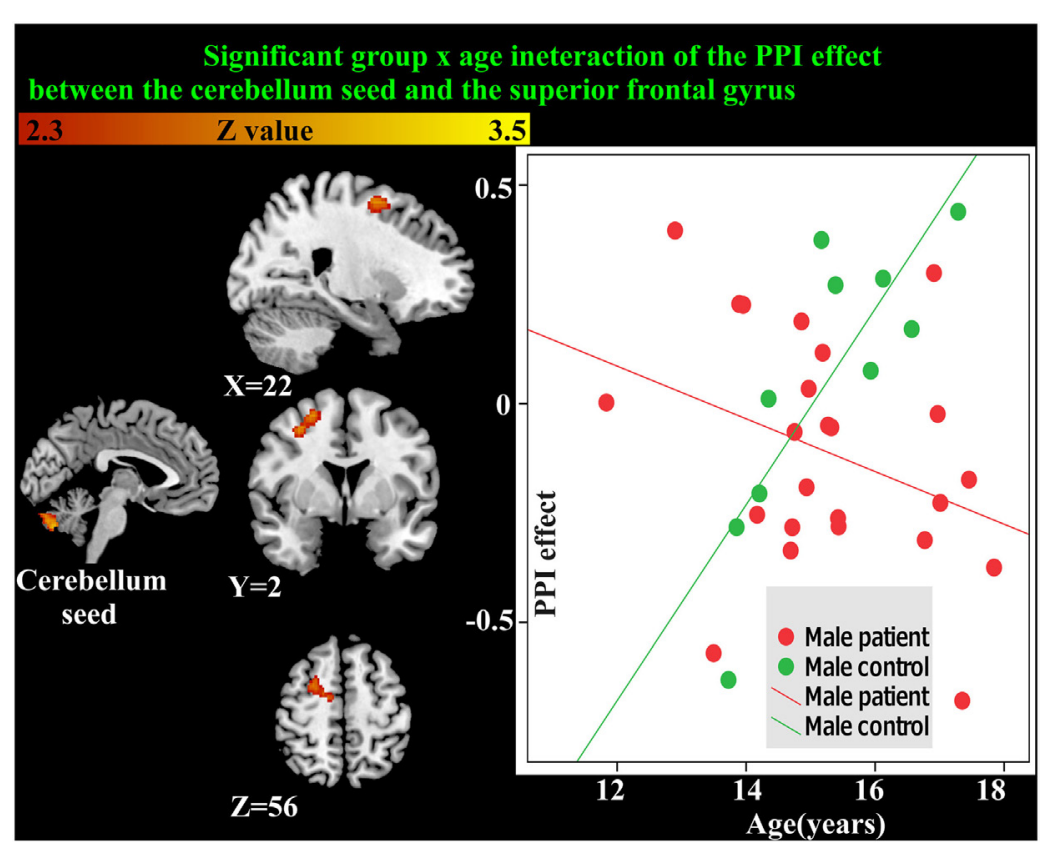

FIGURE 5 | Significant group $\times$ age interaction of the psychophysiological interaction (PPI) connectivity between the cerebellum seed and superior frontal gyrus is shown. With age, connectivity increases in strength in male controls but decreases in strength in males with major depressive disorder.

orbitofrontal cortex as hypothesized. Future studies examining sex differences in adolescent MDD with larger male control groups are needed. Since our significant results were not all hypothesized (e.g., cerebellum), they should be considered preliminary until replicated. Furthermore, although alcohol and drug dependence were among the exclusion criteria, we were unable to explore the possible confounding effects of alcohol and drug since details of frequency or severity of usage were not recorded. 
Most of the significant findings in this study reside in the neuroimaging data, but not in the behavioral data. Our task was designed to be primarily sensitive to brain activation rather than to measure variability in behavior. Discrepancy between behavioral performance and brain activations is frequently reported in the psychiatric fMRI literature, possibly related to the higher sensitivity of brain signals to detect case-control differences or alternative neural strategies to achieve comparable performances in the patient and control groups (38).

Finally, a cross-sectional design was used in this research and although we examine age effects and interactions, we cannot describe the developmental trajectory of our findings with the same confidence that could be drawn from a longitudinal study. Furthermore, we cannot exclude the potential effect of normal developmental sex differences in the cerebellum. Also, pubertal stage was not considered in the analysis. Future research should incorporate these factors into a longitudinal design.

\section{Future Research: The Default Network}

Although network inference was restricted by task design and the fact that the majority of the analyses were univariate in nature, the supramarginal gyrus, PCC, Crus I, and Crus II of the cerebellum, and superior frontal gyrus all contribute to the default network. Indeed, aberrant brain activation of the default network toward negative pictures has been found with an increase of selfreferential focus in MDD (77). Current research also indirectly indicates the importance of default network in the sex differences in MDD. First, men are found to be more liable to persistent MDD whereas women are more likely to suffer from episodic MDD (8). Furthermore, it has been proposed that the default network acts as an overarching mechanism for the impaired cognitive control of recurrent MDD (78). Second, the default network has been regarded as the key to cognitive decline in MDD (79) with men more liable to the cognitive effects of the disorder leading to dementia $(80,81)$. Future research might consider using multivariate analysis to directly explore the relationship between the default network and sex differences in MDD.

\section{CONCLUSION}

Our study provides the first neuroimaging evidence of sex differences observed with functional imaging in adolescent MDD. In response to sad relative to neutral distractors, group-by-sex interactions were found in the supramarginal gyrus and the PCC. In particular, novel aberrant brain activation in the cerebellum with a group-by-age interaction of its connectivity with the superior frontal gyrus was identified in male adolescents with

\section{REFERENCES}

1. Cyranowski JM, Frank E, Young E, Shear MK. Adolescent onset of the gender difference in lifetime rates of major depression: a theoretical model. Arch Gen Psychiatry (2000) 57(1):21-7. doi:10.1001/archpsyc.57.1.21

2. Derry HM, Padin AC, Kuo JL, Hughes S, Kiecolt-Glaser JK. Sex differences in depression: does inflammation play a role? Curr Psychiatry Rep (2015) 17(10):618. doi:10.1007/s11920-015-0618-5

3. Thapar A, Collishaw S, Pine DS, Thapar AK. Depression in adolescence. Lancet (2012) 379:1056-67. doi:10.1016/S0140-6736(11)60871-4
MDD. Future research may explore the neural mechanisms of sex differences and their relationships with clinical symptomology.

\section{ETHICS STATEMENT}

This study was carried out in accordance with the recommendations of Cambridgeshire 2 Research Ethics Committee with written informed consent from all subjects. All subjects gave written informed consent in accordance with the Declaration of Helsinki. The protocol was approved by the Cambridgeshire 2 Research Ethics Committee.

\section{AUTHOR CONTRIBUTIONS}

EB, BL, BS, IG, and JS conceived and designed the experiment. $\mathrm{CH}$, JG, RH, and AN collected the data. J-YC, CO, and RT analyzed the data, with advice from JS and GM. J-YC, JS, RE, and GM drafted the manuscript. All the authors critically reviewed the manuscript.

\section{ACKNOWLEDGMENTS}

The authors appreciate technical help from Dr. Peter Watson, Dr. Anderson M. Winkler, and Dr. Stuart Rankin. This work was performed using the Darwin Supercomputer of the University of Cambridge High Performance Computing Service (http:// www.hpc.cam.ac.uk/), provided by Dell Inc. using Strategic Research Infrastructure Funding from the Higher Education Funding Council for England and funding from the Science and Technology Facilities Council.

\section{FUNDING}

The study was funded by the Medical Research Council (grant: G0802226). The IMPACT clinical trial was funded by the NHSHealth Technology Assessment (HTA) Programme, Central Manchester and Manchester Children's University Hospitals NHS Trust, and the Cambridge and Peterborough Mental Health Trust. Additional support was provided by the jointly funded Medical Research Council/Wellcome Trust Behavioural and Clinical Neuroscience Institute, University of Cambridge, and the National Institute for Health Research (NIHR) Cambridge Biomedical Research Centre.

\section{SUPPLEMENTARY MATERIAL}

The Supplementary Material for this article can be found online at http://journal.frontiersin.org/article/10.3389/fpsyt.2017.00119/ full\#supplementary-material.

4. Flint J, Kendler KS. The genetics of major depression. Neuron (2014) 81(3):484-503. doi:10.1016/j.neuron.2014.01.027

5. Kendler KS, Gardner CO. Sex differences in the pathways to major depression: a study of opposite-sex twin pairs. Am J Psychiatry (2014) 171(4):426-35. doi:10.1176/appi.ajp.2013.13101375

6. Piccinelli M, Wilkinson G. Gender differences in depression: critical review. Br J Psychiatry (2000) 177(6):486-92. doi:10.1192/bjp.177.6.486

7. Kendler KS, Thornton LM, Prescott CA. Gender differences in the rates of exposure to stressful life events and sensitivity to their depressogenic effects. Am J Psychiatry (2001) 158(4):587-93. doi:10.1176/appi.ajp.158.4.587 
8. Dunn V, Goodyer IM. Longitudinal investigation into childhood- and adolescence-onset depression: psychiatric outcome in early adulthood. $\mathrm{Br}$ J Psychiatry (2006) 188:216-22. doi:10.1192/bjp.188.3.216

9. Morgan JK, Shaw DS, Olino TM, Musselman SC, Kurapati NT, Forbes EE. History of depression and frontostriatal connectivity during reward processing in late adolescent boys. J Clin Child Adolesc Psychol (2016) 45(1):59-68. doi:10.1080/15374416.2015.1030753

10. Marcus SM, Young EA, Kerber KB, Kornstein S, Farabaugh AH, Mitchell $J$, et al. Gender differences in depression: findings from the STAR ${ }^{\star} \mathrm{D}$ study. J Affect Disord (2005) 87(2-3):141-50. doi:10.1016/j.jad.2004.09.008

11. Richard-Devantoy S, Berlim MT, Jollant F. A meta-analysis of neuropsychological markers of vulnerability to suicidal behavior in mood disorders. Psychol Med (2014) 44(8):1663-73. doi:10.1017/S0033291713002304

12. Garavan H, Stout JC. Neurocognitive insights into substance abuse. Trends Cogn Sci (2005) 9(4):195-201. doi:10.1016/j.tics.2005.02.008

13. Koch K, Pauly K, Kellermann T, Seiferth NY, Reske M, Backes V, et al. Gender differences in the cognitive control of emotion: an fMRI study. Neuropsychologia (2007) 45(12):2744-54. doi:10.1016/j.neuropsychologia.2007.04.012

14. Crone EA, Dahl RE. Understanding adolescence as a period of social-affective engagement and goal flexibility. Nat Rev Neurosci (2012) 13(9):636-50. doi:10.1038/nrn3313

15. Beck AT, Rush AJ, Shaw BF, Emery G. Cognitive therapy of depression. Cogn Ther Depression. New York: The Guilford Press (1979):425.

16. Everaert J, Koster EHW, Derakshan N. The combined cognitive bias hypothesis in depression. Clin Psychol Rev (2012) 32(5):413-24. doi:10.1016/j. cpr.2012.04.003

17. Vanderhasselt M-A, Kühn S, De Raedt R. Healthy brooders employ more attentional resources when disengaging from the negative: an event-related fMRI study. Cogn Affect Behav Neurosci (2011) 11:207-16. doi:10.3758/ s13415-011-0022-5

18. Vercammen A, Morris R, Green MJ, Lenroot R, Kulkarni J, Carr VJ, et al. Reduced neural activity of the prefrontal cognitive control circuitry during response inhibition to negative words in people with schizophrenia. J Psychiatry Neurosci (2012) 37:379-88. doi:10.1503/jpn.110088

19. Elliott R, Rubinsztein JS, Sahakian BJ, Dolan RJ. Selective attention to emotional stimuli in a verbal go/no-go task: an fMRI study. Neuroreport (2000) 11:1739-44. doi:10.1097/00001756-200006050-00028

20. Schulz KP, Clerkin SM, Fan J, Halperin JM, Newcorn JH. Guanfacine modulates the influence of emotional cues on prefrontal cortex activation for cognitive control. Psychopharmacology (2013) 226(2):261-71. doi:10.1007/ s00213-012-2893-8

21. van Holst RJ, van Holstein M, van den Brink W, Veltman DJ, Goudriaan AE. Response inhibition during cue reactivity in problem gamblers: an fMRI study. PLoS One (2012) 7:e30909. doi:10.1371/journal.pone.0030909

22. Schulz KP, Clerkin SM, Halperin JM, Newcorn JH, Tang CY, Fan J. Dissociable neural effects of stimulus valence and preceding context during the inhibition of responses to emotional faces. Hum Brain Mapp (2009) 30:2821-33. doi:10.1002/hbm.20706

23. Goldstein M, Brendel G, Tuescher O, Pan H, Epstein J, Beutel M, et al. Neural substrates of the interaction of emotional stimulus processing and motor inhibitory control: an emotional linguistic go/no-go fMRI study. Neuroimage (2007) 36:1026-40. doi:10.1016/j.neuroimage.2007.01.056

24. Somerville LH, Hare T, Casey BJ. Frontostriatal maturation predicts cognitive control failure to appetitive cues in adolescents. J Cogn Neurosci (2011) 23:2123-34. doi:10.1162/jocn.2010.21572

25. Shafritz KM, Collins SH, Blumberg HP. The interaction of emotional and cognitive neural systems in emotionally guided response inhibition. Neuroimage (2006) 31:468-75. doi:10.1016/j.neuroimage.2005.11.053

26. Buchsbaum BR, Greer S, Chang W-L, Berman KF. Meta-analysis of neuroimaging studies of the Wisconsin card-sorting task and component processes. Hum Brain Mapp (2005) 25:35-45. doi:10.1002/hbm.20128

27. Criaud $M$, Boulinguez $P$. Have we been asking the right questions when assessing response inhibition in go/no-go tasks with fMRI? A meta-analysis and critical review. Neurosci Biobehav Rev (2013) 37(1):11-23. doi:10.1016/j. neubiorev.2012.11.003

28. Nee DE, Wager TD, Jonides J. Interference resolution: insights from a meta-analysis of neuroimaging tasks. Cogn Affect Behav Neurosci (2007) 7:1-17. doi:10.3758/CABN.7.1.1
29. Simmonds DJ, Pekar JJ, Mostofsky SH. Meta-analysis of go/no-go tasks demonstrating that fMRI activation associated with response inhibition is task-dependent. Neuropsychologia (2008) 46:224-32. doi:10.1016/j. neuropsychologia.2007.07.015

30. Swick D, Ashley V, Turken U. Are the neural correlates of stopping and not going identical? Quantitative meta-analysis of two response inhibition tasks. Neuroimage (2011) 56:1655-65. doi:10.1016/j.neuroimage.2011.02.070

31. Behan B, Connolly CG, Datwani S, Doucet M, Ivanovic J, Morioka R, et al. Response inhibition and elevated parietal-cerebellar correlations in chronic adolescent cannabis users. Neuropharmacology (2014) 84:131-7. doi:10.1016/ j.neuropharm.2013.05.027

32. Lock J, Garrett A, Beenhakker J, Reiss AL. Aberrant brain activation during a response inhibition task in adolescent eating disorder subtypes. Am J Psychiatry (2011) 168:55-64. doi:10.1176/appi.ajp.2010.10010056

33. Nosarti C, Rubia K, Smith AB, Frearson S, Williams SC, Rifkin L, et al. Altered functional neuroanatomy of response inhibition in adolescent males who were born very preterm. Dev Med Child Neurol (2006) 48:265-71. doi:10.1017/ S0012162206000582

34. Rubia K, Smith AB, Woolley J, Nosarti C, Heyman I, Taylor E, et al. Progressive increase of frontostriatal brain activation from childhood to adulthood during event-related tasks of cognitive control. Hum Brain Mapp (2006) 27:973-93. doi:10.1002/hbm.20237

35. Wetherill RR, Castro N, Squeglia LM, Tapert SF. Atypical neural activity during inhibitory processing in substance-naïve youth who later experience alcohol-induced blackouts. Drug Alcohol Depend (2013) 128(3):243-9. doi:10.1016/j.drugalcdep.2012.09.003

36. Wetherill RR, Squeglia LM, Yang TT, Tapert SF. A longitudinal examination of adolescent response inhibition: neural differences before and after the initiation of heavy drinking. Psychopharmacology (Berl) (2013) 230:663-71. doi:10.1007/s00213-013-3198-2

37. Elliott R, Rubinsztein JS, Sahakian BJ, Dolan RJ. The neural basis of mood-congruent processing biases in depression. Arch Gen Psychiatry (2002) 59:597-604. doi:10.1001/archpsyc.59.7.597

38. Chuang J-Y, J Whitaker K, Murray GK, Elliott R, Hagan CC, Graham JM, et al. Aberrant brain responses to emotionally valent words is normalised after cognitive behavioural therapy in female depressed adolescents. J Affect Disord (2016) 189:54-61. doi:10.1016/j.jad.2015.09.008

39. Mayberg HS. Modulating dysfunctional limbic-cortical circuits in depression: towards development of brain-based algorithms for diagnosis and optimised treatment. Br Med Bull (2003) 65:193-207. doi:10.1093/bmb/65.1.193

40. Goodyer IM, Tsancheva S, Byford S, Dubicka B, Hill J, Kelvin R, et al. Improving mood with psychoanalytic and cognitive therapies (IMPACT): a pragmatic effectiveness superiority trial to investigate whether specialised psychological treatment reduces the risk for relapse in adolescents with moderate to severe unipolar depres. Trials (2011) 12(1):175. doi:10.1186/1745-6215-12-175

41. Hagan CC, Graham JM, Widmer B, Holt RJ, Ooi C, van Nieuwenhuizen AO, et al. Magnetic resonance imaging of a randomized controlled trial investigating predictors of recovery following psychological treatment in adolescents with moderate to severe unipolar depression: study protocol for Magnetic Resonance-Improving Mood with Psycho. BMC Psychiatry (2013) 13(1):247. doi:10.1186/1471-244X-13-247

42. Angold A, Costello E, Pickles A, Winder F, Silver D. The development of a questionnaire for use in epidemiological studies of depression in children and adolescents. London: Medical Research Council Child Psychiatry Unit (1987).

43. Hofland K, Johansson S. Word Frequencies in British and American English. Oslo: Norwegian Computing Centre for the Humanities (1982).

44. Jenkinson M, Bannister P, Brady M, Smith S. Improved optimization for the robust and accurate linear registration and motion correction of brain images. Neuroimage (2002) 17:825-41. doi:10.1016/S1053-8119(02) 91132-8

45. Smith SM. Fast robust automated brain extraction. Hum Brain Mapp (2002) 17:143-55. doi:10.1002/hbm.10062

46. Worsley KJ. Functional MRI: an introduction to methods. In: Jezzard P, Matthews PM, Smith SM, editors. Statistical Analysis of Activation Images. New York: Oxford University Press (2001).

47. Jenkinson M, Smith S. A global optimisation method for robust affine registration of brain images. Med Image Anal (2001) 5(2):143-56. doi:10.1016/ S1361-8415(01)00036-6 
48. Winkler AM, Ridgway GR, Webster MA, Smith SM, Nichols TE. Permutation inference for the general linear model. Neuroimage (2014) 92:381-97. doi:10.1016/j.neuroimage.2014.01.060

49. O'Reilly JX, Woolrich MW, Behrens TEJ, Smith SM, Johansen-Berg H. Tools of the trade: psychophysiological interactions and functional connectivity. Soc Cogn Affect Neurosci (2012) 7(5):604-9. doi:10.1093/scan/nss055

50. Rubia K, Russell T, Overmeyer S, Brammer MJ, Bullmore ET, Sharma T, et al. Mapping motor inhibition: conjunctive brain activations across different versions of go/no-go and stop tasks. Neuroimage (2001) 13(2):250-61. doi:10.1006/nimg.2000.0685

51. Cohen-Gilbert JE, Thomas KM. Inhibitory control during emotional distraction across adolescence and early adulthood. Child Dev (2013) 84(6):1954-66. doi:10.1111/cdev.12085

52. Kadosh KC, Heathcote LC, Lau JYF. Age-related changes in attentional control across adolescence: how does this impact emotion regulation capacities? Front Psychol (2014) 5:111. doi:10.3389/fpsyg.2014.00111

53. Sankar A, Scott J, Paszkiewicz A, Giampietro VP, Steiner H, Fu CHY. Neural effects of cognitive-behavioural therapy on dysfunctional attitudes in depression. Psychol Med (2015) 45(7):1425-33. doi:10.1017/ S0033291714002529

54. Groenewold NA, Opmeer EM, de Jonge P, Aleman A, Costafreda SG. Emotional valence modulates brain functional abnormalities in depression: evidence from a meta-analysis of fMRI studies. Neurosci Biobehav Rev (2013) 37:152-63. doi:10.1016/j.neubiorev.2012.11.015

55. Ho TC, Connolly CG, Henje Blom E, LeWinn KZ, Strigo IA, Paulus MP, et al. Emotion-dependent functional connectivity of the default mode network in adolescent depression. Biol Psychiatry (2014) 78(9):635-46. doi:10.1016/j. biopsych.2014.09.002

56. Frederikse ME, Lu A, Aylward E, Barta P, Pearlson G. Sex differences in the inferior parietal lobule. Cereb Cortex (1999) 9:896-901. doi:10.1093/ cercor/9.8.896

57. Xu C, Li C, Wu H, Wu Y, Hu S, Zhu Y, et al. Gender differences in cerebral regional homogeneity of adult healthy volunteers: a resting-state fMRI study. Biomed Res Int (2015) 2015:183074. doi:10.1155/2015/183074

58. Hofer A, Siedentopf CM, Ischebeck A, Rettenbacher MA, Verius M, Felber S, et al. Sex differences in brain activation patterns during processing of positively and negatively valenced emotional words. Psychol Med (2007) 37(1):109-19. doi:10.1017/S0033291706008919

59. Van Duijvenvoorde ACK, Crone EA. The teenage brain: a neuroeconomic approach to adolescent decision making. Curr Dir Psychol Sci (2013) 22:108-13. doi:10.1177/0963721413475446

60. Leech R, Sharp DJ. The role of the posterior cingulate cortex in cognition and disease. Brain (2014) 137:12-32. doi:10.1093/brain/awt162

61. Ruigrok ANV, Salimi-Khorshidi G, Lai M-C, Baron-Cohen S, Lombardo $\mathrm{MV}$, Tait RJ, et al. A meta-analysis of sex differences in human brain structure. Neurosci Biobehav Rev (2014) 39:34-50. doi:10.1016/j. neubiorev.2013.12.004

62. Andreasen NC, Pierson R. The role of the cerebellum in schizophrenia. Biol Psychiatry (2008) 64:81-8. doi:10.1016/j.biopsych.2008.01.003

63. Singer T, Seymour B, O’Doherty J, Kaube H, Dolan RJ, Frith CD. Empathy for pain involves the affective but not sensory components of pain. Science (2004) 303:1157-62. doi:10.1126/science.1093535

64. Stoodley CJ, Schmahmann JD. Evidence for topographic organization in the cerebellum of motor control versus cognitive and affective processing. Cortex (2010) 46:831-44. doi:10.1016/j.cortex.2009.11.008

65. Dolan RJ, Bench CJ, Brown RG, Scott LC, Friston KJ, Frackowiak RS. Regional cerebral blood flow abnormalities in depressed patients with cognitive impairment. J Neurol Neurosurg Psychiatry (1992) 55:768-73. doi:10.1136/ jnnp.55.9.768

66. Graham J, Salimi-Khorshidi G, Hagan C, Walsh N, Goodyer I, Lennox B, et al. Meta-analytic evidence for neuroimaging models of depression: state or trait? J Affect Disord (2013) 151:423-31. doi:10.1016/j.jad.2013.07.002

67. Iwabuchi SJ, Krishnadas R, Li C, Auer DP, Radua J, Palaniyappan L. Localized connectivity in depression: a meta-analysis of resting state functional imaging studies. Neurosci Biobehav Rev (2015) 51:77-86. doi:10.1016/j. neubiorev.2015.01.006
68. Tiemeier H, Lenroot RK, Greenstein DK, Tran L, Pierson R, Giedd JN. Cerebellum development during childhood and adolescence: a longitudinal morphometric MRI study. Neuroimage (2010) 49:63-70. doi:10.1016/j. neuroimage.2009.08.016

69. Chantiluke K, Halari R, Simic M, Pariante CM, Papadopoulos A, Giampietro $\mathrm{V}$, et al. Fronto-striato-cerebellar dysregulation in adolescents with depression during motivated attention. Biol Psychiatry (2012) 71(1):59-67. doi:10.1016/j. biopsych.2011.09.005

70. Pilhatsch M, Vetter NC, Hübner T, Ripke S, Müller KU, Marxen M, et al. Amygdala-function perturbations in healthy mid-adolescents with familial liability for depression. J Am Acad Child Adolesc Psychiatry (2014) 53(5):55968. doi:10.1016/j.jaac.2014.02.010

71. Buckner RL, Krienen FM, Castellanos A, Diaz JC, Yeo BTT. The organization of the human cerebellum estimated by intrinsic functional connectivity. J Neurophysiol (2011) 106(5):2322-45. doi:10.1152/jn.00339.2011

72. Kaiser RH, Andrews-Hanna JR, Wager TD, Pizzagalli DA. Large-scale network dysfunction in major depressive disorder. JAMA Psychiatry (2015) 2478(6):603-11. doi:10.1001/jamapsychiatry.2015.0071

73. Guo W, Liu F, Liu J, Yu M, Zhang Z, Liu G, et al. Increased cerebellar-default-mode-network connectivity in drug-naive major depressive disorder at rest. Medicine (Baltimore) (2015) 94(9):e560. doi:10.1097/ MD. 0000000000000560

74. Guo W, Liu F, Xue Z, Gao K, Liu Z, Xiao C, et al. Abnormal resting-state cerebellar-cerebral functional connectivity in treatment-resistant depression and treatment sensitive depression. Prog Neuropsychopharmacol Biol Psychiatry (2013) 44:51-7. doi:10.1016/j.pnpbp.2013.01.010

75. Zeng LL, Shen H, Liu L, Wang L, Li B, Fang P, et al. Identifying major depression using whole-brain functional connectivity: a multivariate pattern analysis. Brain (2012) 135(5):1498-507. doi:10.1093/brain/aws059

76. Alalade E, Denny K, Potter G, Steffens D, Wang L. Altered cerebellar-cerebral functional connectivity in geriatric depression. PLoS One (2011) 6(5):e20035. doi:10.1371/journal.pone.0020035

77. Sheline YI, Barch DM, Price JL, Rundle MM, Vaishnavi SN, Snyder AZ, et al. The default mode network and self-referential processes in depression. Proc Natl Acad Sci U S A (2009) 106(6):1942-7. doi:10.1073/pnas.0812686106

78. Marchetti I, Koster EHW, Sonuga-Barke EJ, De Raedt R. The default mode network and recurrent depression: a neurobiological model of cognitive risk factors. Neuropsychol Rev (2012) 22(3):229-51. doi:10.1007/ s11065-012-9199-9

79. Royall DR, Palmer RF, Vidoni ED, Honea RA. The default mode network may be the key substrate of depressive symptom-related cognitive changes. J Alzheimers Dis (2013) 34(2):547-59. doi:10.3233/JAD-121639

80. Dal Forno G, Palermo MT, Donohue JE, Karagiozis H, Zonderman AB, Kawas $\mathrm{CH}$. Depressive symptoms, sex, and risk for Alzheimer's disease. Ann Neurol (2005) 57:381-7. doi:10.1002/ana.20405

81. Fuhrer R, Dufouil C, Dartigues JF, PAQUID Study. Exploring sex differences in the relationship between depressive symptoms and dementia incidence: prospective results from the PAQUID Study. JAm Geriatr Soc (2003) 51(8):1055-63. doi:10.1046/j.1532-5415.2003.51352.x

Conflict of Interest Statement: BS reports personal fees from Cambridge Cognition, personal fees and other from Lundbeck, personal fees from Servier, grants from J\&J Janssen, other from Otsuka, personal fees from Peak (Brainbow), outside the submitted work; EB works half-time for the University of Cambridge and half-time for GlaxoSmithKline. He holds stock in GlaxoSmithKline; IG reports personal fees from Lundbeck and holds grants from the Wellcome Trust and the Friends of Peterhouse Charity and NIHR-HTA. All other authors declare no conflict of interest.

Copyright (๑) 2017 Chuang, Hagan, Murray, Graham, Ooi, Tait, Holt, Elliott, van Nieuwenhuizen, Bullmore, Lennox, Sahakian, Goodyer and Suckling. This is an open-access article distributed under the terms of the Creative Commons Attribution License (CC BY). The use, distribution or reproduction in other forums is permitted, provided the original author(s) or licensor are credited and that the original publication in this journal is cited, in accordance with accepted academic practice. No use, distribution or reproduction is permitted which does not comply with these terms. 